\title{
Proceeding
}

Supplementary Issue: Rio 2016 Olympic Games Second Anniversary Special Edition. Olympic Studies Forum, 2-3 October 2018.

Federal University of Espirito Santo, (Vitória - Espírito Santo), Brazil

\section{Report of a preventive intervention based on cognitive-behavioural therapy and positive psychology for adolescent athletes}

\author{
ARTUR MARQUES STREY ${ }^{1} \triangle$, DANIELE LINDERN ${ }^{1}$, CAROLINA SARAIVA DE MACEDO LISBOA ${ }^{2}$ \\ ${ }^{1}$ School of Health Sciences, Pontifical Catholic University of Rio Grande do Sul (PUCRS), Porto Alegre, Brazil \\ ${ }^{2}$ Faculty of Psychology, Pontifical Catholic University of Rio Grande do Sul (PUCRS), Porto Alegre, Brazil
}

\begin{abstract}
This study aimed to report the experience of a group intervention, with a preventive focus on anxiety and maladaptive behaviours and aimed at improving social and coping skills and at promoting well-being for soccer athletes from basic categories. Eight sessions of intervention were performed, each lasting 90 minutes, structured in the Cognitive-behavioural Therapy model and with weekly frequency. The results indicate that the athletes had a high level of achievement of the meetings that aimed at psychoeducation and practiced management skills of anxiety, social skills and cognitive distortions. Keywords: Experience report; Cognitive-behavioural therapy, Positive psychology, Sports psychology, Adolescence.
\end{abstract}

\section{Cite this article as:}

Marques, A., Lindern, D. \& De Macedo, C.S. (2019). Report of a preventive intervention based on cognitive-behavioural therapy and positive psychology for adolescent athletes (in Portuguese). Journal of Human Sport and Exercise, 14(3proc), S423-S434. doi:https://doi.org/10.14198/ihse.2019.14.Proc3.14

Corresponding author. Avenida Wenceslau Escobar, 3714, casa 13. Bairro Tristeza. CEP: 91900001. Porto Alegre, Rio Grande do Sul. Brazil.

E-mail: arthur.mstrey@gmail.com

Supplementary Issue: Rio 2016 Olympic Games Second Anniversary Special Edition. Olympic Studies Forum, 2-3 October 2018. Federal University of Espírito Santo, (Vitória - Espírito Santo), Brazil.

JOURNAL OF HUMAN SPORT \& EXERCISE ISSN 1988-5202

(C) Faculty of Education. University of Alicante

doi:10.14198/jhse.2019.14.Proc3.14 


\section{INTRODUÇÃO}

Atletas de futebol estão expostos a diversos fatores de risco impostos pelo contexto esportivo, como treinamentos, viagens, jogos, lesões, abdicação de vivências próprias da idade, abandono dos estudos, problemas pessoais e interpessoais, ansiedade e estresse pré-competições (Nascimento Junior, Gaion, Nakashima e Vieira, 2011). O estresse pode ser compreendido como uma reação do organismo frente a uma mudança no ambiente a qual exige grande adaptação do sujeito (Silva et al, 2017). Quando confrontado com um estressor, o sujeito depara-se com um estado de tensão mental e física o qual induz a um desequilíbrio no funcionamento do organismo enfraquecendo seu sistema imunológico, deixando-o propenso a infecções e doenças (Santos et al., 2017). Entretanto, Lipp (2014) afirma que todos podem adquirir estratégias para manejar e adaptarem-se às situações estressoras, seja por meio do estudo referente à temática ou de um processo terapêutico.

No que tange 0 esporte de alto rendimento, a literatura aponta que o estresse e a ansiedade podem causar sintomas de sofrimento (Caputo, Rombaldi e Silva, 2017). Porém, situações de estresse podem motivar fisiológica e psicologicamente, preparando o atleta para um desempenho ótimo, corroborando a ideia de que 0 estresse pode muitas vezes proporcionar reações adaptativas dependendo da maneira como cada indivíduo reage ao agente estressor. Ainda, aponta-se que são escassos os estudos realizados no contexto brasileiro que abordem as diferentes estratégias de adaptação de atletas de categoria de base ao estresse psicológico pré-competitivo (Nascimento Junior, Gaion, Nakashima e Vieira, 2011).

Intervenções voltadas à promoção de saúde mental no contexto futebolístico são ainda bastante escassas na literatura, sendo mais comumente encontrados estudos voltados à prevenção de lesões (por exemplo, Engebretsen, Myklebust, Holme, Engebretsen, e Bahr, 2008; Steffen, Bakka, Myklebust, e Bahr, 2008; Van Beijsterveldt, Van der Horst, Van de Port, e Backx, 2013). No entanto, as peculiaridades deste contexto apontam para potenciais fatores de risco que tornam urgente o estudo das demandas psicológicas de atletas, principalmente aos adolescentes aspirantes a profissionais, que em muitos casos deixam sua família para morar em residências esportivas das categorias de base dos clubes de futebol - que contemplam atletas de 12 a 20 anos de idade (Paína, Fechio, Peccin e Padovani, 2018).

A etapa do desenvolvimento a qual os atletas de categoria de base se encontram mostra-se muito crítica por ser definitiva no processo de formação e consolidação de uma identidade pessoal (Rodríguez e Damásio, 2014). A adolescência pode configurar-se como um período de vulnerabilidade, considerando que muitas vezes o jovem, que atravessa um processo de mudanças biopsicossociais, apresenta dificuldades em lançar mão de seus recursos para adaptar-se ao seu contexto social, levando-o a uma condição desfavorável (Luz, Murta e Aquino, 2015). Desta forma, tendo em vista a complexidade e a quantidade de demandas que esta fase da vida impõe, adicionando os fatores de risco presentes no contexto esportivo, como o estresse pré-competitivo, torna-se necessária a implementação de intervenções preventivas de saúde mental para está população.

A promoção preventiva no âmbito da saúde mental tem ganhado foco desde o lançamento do relatório da OMS abordando a temática de intervenções e políticas possíveis para a prevenção de doenças mentais (WHO, 2001). Segundo Murta (2007), as metas a serem estabelecidas em um programa com foco preventivo podem visar tanto à redução de problemas quanto o aumento de competências. Considerando estes dois objetivos, ressalta-se a importância da utilização de conhecimentos científicos consolidados dentro da Psicologia para embasar as intervenções que buscam atingi-los. 
Sendo assim, no que tange à abordagem teórica destas intervenções, a Terapia Cognitivo-comportamental (TCC) mostra-se promissora no quesito de resolução de problemas, por ser a abordagem com o maior número de pesquisas confirmando sua efetividade (Butler, Chapman, Forman e Beck, 2006). A TCC pressupõe que compreendendo o modelo cognitivo, ou seja, a forma como cognições afetam emoções e comportamentos, um indivíduo pode substituir percepções equivocadas sobre suas vivências por compreensões mais adaptativas (Knapp e Beck, 2008). A TCC parte do princípio que os indivíduos podem aprender habilidades para a vida, como habilidades sociais e habilidades de coping ou enfrentamento (formas de lidar com situações de estresse), monitorar e modificar suas compreensões enviesadas de experiências de vida (também chamadas de distorções cognitivas), conhecer seu funcionamento, prevenindo, assim, futuros transtornos (Wright, Basco e Thase, 2008).

Uma intervenção que tenha como foco a prevenção e a promoção de saúde deve não somente focar-se no desenvolvimento de habilidades, mas também nos fatores de proteção enquanto potencializadores do bemestar. Dentre os fatores de proteção presentes no contexto esportivo, podem ser citados, por exemplo, a proximidade de técnicos, treinadores e colegas, aumento da autoestima e autoconfiança, motivação e competência social, maior responsabilidade, atribuição de uma função social e estabelecimentos de metas pessoais (Sanches, 2007). Nesta perspectiva, a Psicologia Positiva propõe-se como um paradigma que busca desenvolver um conhecimento teórico e diretrizes técnicas sobre os processos e condições que favorecem o bem-estar de indivíduos e comunidades, considerando a importância do olhar aos aspectos saudáveis de cada indivíduo (Paludo e Koller, 2007). Desta forma, a Psicologia Positiva enfatiza a importância do estudo e intervenção junto às virtudes e forças pessoais dos seres humanos, além de elementos do bem-estar como emoções positivas, relacionamentos positivos, engajamento, sentido e realização, reconhecendo estes fatores como agentes preventivos e protetores de transtornos mentais (Sanches, 2018).

Considerando-se este contexto, o objetivo deste estudo foi descrever uma intervenção com foco preventivo à ansiedade e comportamentos desadaptativos e que visava ao aprimoramento de habilidades sociais e de coping e à promoção de bem-estar para atletas de futebol de categorias de base, baseada nos preceitos da TCC e da Psicologia Positiva.

\section{MÉTODO}

\section{Participantes}

Para esta intervenção, foram definidas como população alvo as categorias de base Sub-15 e Sub-16, em virtude de na ocasião da coleta de dados possuírem horários livres compatíveis com os pesquisadores. Para a seleção dos participantes, foi realizado um sorteio com os atletas da Sub-15 e Sub-16, visando a divisão em um grupo de intervenção $(n=10)$ e em um grupo de comparação $(n=10)$. Por caracterizar-se como uma intervenção universal, a mesma foi desenvolvida com a finalidade de ser replicável a quaisquer atletas de futebol, não havendo critérios de exclusão ou inclusão para participação. Neste sentido, participaram da intervenção os jovens que receberam autorização dos pais para participar do estudo e que concordaram em participar do trabalho proposto.

\section{Procedimentos}

Após a instituição conceder anuência para a realização do estudo com os participantes, o projeto foi enviado para o Comitê de Ética em Pesquisa da Pontifícia Universidade Católica do Rio Grande do Sul - PUCRS, e aprovado sob o protocolo $n^{0} 1.021 .701 / 2015$. Posteriormente, foi feito o sorteio com os atletas das categorias de base Sub-15 e Sub-16, e solicitada autorização por meio do Termo de Consentimento Livre e Esclarecido 
(TCLE), entregue para os responsáveis, e do Termo de Assentimento, entregue para os participantes. 0 grupo de intervenção participou da intervenção, e o grupo de comparação não recebeu nenhum tipo de intervenção. Ressalta-se que por não serem identificadas demandas de sofrimento específico, os atletas do grupo de comparação não foram prejudicados. Foi oferecida a intervenção para o grupo de comparação em um momento posterior, porém a maioria dos atletas havia sido dispensados (demitidos) do clube, além de não terem compatibilidade de horários para a realização do trabalho. $O$ grupo foi coordenado por duas psicólogas em formação em TCC, acompanhadas de um aluno bolsista de iniciação científica do referido projeto, que observou os encontros e anotou suas impressões em um diário de campo.

Todos os participantes foram avaliados antes e após a intervenção em suas habilidades sociais, habilidades de coping, bem-estar estar subjetivo (afetos positivos e negativos e satisfação de vida) e ansiedade. 0 detalhamento dos instrumentos utilizados e análise quantitativa da comparação dos resultados pré e pósintervenção estão descritos de forma detalhada em outra publicação.

A intervenção foi realizada em grupo, modalidade mais indicada por facilitar tanto a aprendizagem de habilidades sociais quanto outras habilidades, visto que o grupo propicia a modelagem pela observação dos participantes, além de ser capaz de gerar novos repertórios sociais (Bieling, McCabe e Antony, 2008). Foram realizadas oito sessões de intervenção, com duração de 90 minutos cada, estruturadas no modelo da TCC e com frequência semanal. Em alguns momentos as sessões tiveram espaçamento quinzenal, em função de variáveis intervenientes que ocorreram ao longo dos encontros (como, por exemplo, campeonatos, convocação para jogos ou outras atividades de caráter obrigatório e que ocorreram sem aviso prévio por parte do clube). As temáticas dos encontros foram acompanhadas de tarefas, entregues ao final de cada sessão, visando ao treino e fixação das temáticas trabalhadas. As tarefas eram sempre retomadas e discutidas no encontro posterior.

A sala onde foi aplicada a intervenção possibilitava que todas as atividades planejadas pudessem ser realizadas (apresentações de Power Point com Datashow, vídeos e dinâmicas de grupo). Todos os encontros contavam com psicoeducação do tema a ser abordado, em apresentação de slides, seguido de um vídeo e/ou dinâmica de grupo, e por fim, eram revisadas as tarefas de casa da semana anterior. A Tabela 1 apresenta os temas de cada sessão da intervenção.

Tabela 1. Temas dos encontros

\begin{tabular}{ll}
\hline Sessões & Temas dos Encontros \\
\hline Sessão 1 & Apresentação e combinações. \\
Sessão 2 & Emoções positivas, Habilidades Sociais (Assertividade), Modelo "Pensamento- \\
Sessão 3 & Emoção-Comportamento". \\
Sessão 4 & Engacionamentos Positivos, Habilidades Sociais (Empatia), Distorções Cognitivas. \\
Sessão 5 & Fatores de Risco, Fatores de Proteção e Resiliência. \\
Sessão 6 & Psicoeducação sobre Estresse e Ansiedade. \\
Sessão 7 & Habilidades de Coping (Treino Respiratório e Respiração Diafragmática, Registro de \\
Sessão 8 & Pensamentos Disfuncionais, Reestruturação Cognitiva, Cartões de Enfrentamento). \\
\hline
\end{tabular}




\section{RESULTADOS}

No encontro inicial, os atletas se mostraram com boas expectativas para a intervenção frente à explicação da proposta, principalmente ao que rege a temática da ansiedade. Também demonstraram engajamento para construir as regras do grupo de forma conjunta. Além disso, se mostraram atentos às explicações das coordenadoras e solícitos aos seus questionamentos e reflexões. Quando elas pediam a opinião deles, envolviam-se ativamente nas discussões, buscando contribuir com as suas percepções. No entanto, foi perceptível que ainda não estavam envolvidos com a proposta, e de certa maneira mostraram-se também desconfiados do porquê foram escolhidos para participar da intervenção, como se estivessem ali por encaminhamento do clube, por ter sido avaliado algum tipo de problema por parte da instituição (apesar das pesquisadoras, em todas as etapas da pesquisa, terem deixado claro que aquele era um trabalho preventivo, aplicável a qualquer atleta de futebol de alto rendimento adolescente, e que eles foram selecionados por meio de sorteio).

Ao longo do encontro os participantes foram se envolvendo mais, talvez por compreender melhor a proposta e perceber que poderia ser útil em seu contexto. No seguimento do encontro, foi realizada a 'dinâmica do barbante', onde os participantes ficam de pé em círculo e o atleta que inicia deve segurar a ponta do barbante e falar de coisas que gosta, e quando termina, lança o barbante para qualquer um dos participantes. Ao final é formada uma teia, a qual é relacionada metaforicamente com as relações grupais, onde todos estão interligados e são importantes para que tenhamos um bom resultado. Em seguida, a teia é desfeita, iniciando pelo último que falou, que devia falar as preferências do participante que lhe lançou o barbante e assim por diante, necessitando que eles tivessem que relembrar a fala do colega anterior. Durante os relatos, alguns aspectos se repetiam nas falas dos participantes, como o prazer de estar com a família, e em segundo lugar com os amigos. Um deles relatou que conversa bastante com seus amigos para não pensar na distância que estava da família, que vive em outro estado. Outros fatores que também apareceram nas apresentações foram o gosto por jogar futebol, assistir filmes, ouvir música, ir ao shopping e passear pela cidade.

No momento da dinâmica, os atletas participaram ativamente, entretanto, não pareciam entusiasmados com a proposta de integração, talvez por já se conhecerem antes do início da intervenção. Porém, pode-se notar que eles se animaram com a possibilidade de fazer atividades práticas durante os encontros. Ao final, os atletas demonstraram alívio pela tarefa de casa consistir apenas na leitura de uma reportagem de jornal, que explicava os elementos do bem-estar da Psicologia Positiva (emoções positivas, relacionamentos positivos, engajamento, sentido e realização) em uma linguagem simples e acessível.

No segundo encontro, iniciou-se o trabalho com os elementos do bem-estar. Pode-se perceber que o grupo interagia menos frente a questionamentos mais abertos, que exigiam que eles dessem suas opiniões sobre os conteúdos (ex: "Qual é a importância do assunto tratado na reportagem?"). Quando foi abordada a temática do bem-estar de forma geral, foi questionado o que fazia que se sentissem bem. Nesse momento, a questão de jogar futebol e serem campeões apareceu. Entretanto, um dos atletas verbalizou que muitas vezes eles são obrigados a deixar de fazer coisas que gostam por ter que cumprir com as obrigações do clube. No seguimento da sessão, quando abordada a temática das emoções positivas e da realização, eles trouxeram reflexões sobre a experiência de jogar futebol e de serem campeões, reconhecendo que essa última é uma vivência que desperta uma emoção mais intensa, porém passageira.

Notou-se que os participantes interagiam mais com perguntas diretas e mais relacionadas ao seu cotidiano (ex: "O que te faz sentir bem no seu dia-a-dia?"), onde eles acabavam por dar sentido às temáticas pelas experiências relatadas pelos outros participantes, debatendo em cima das respostas. Foi realizada a 
psicoeducação sobre os componentes do bem-estar de maneira geral e breve e em seguida foi explicado que todos eles seriam trabalhados ao longo dos encontros.

No terceiro encontro, sobre relacionamentos positivos e habilidades sociais, os participantes chegaram sonolentos e desmotivados, oscilando entre conversas paralelas e brincadeiras e prestar atenção aos conteúdos abordados pelas coordenadoras. No momento em que a apresentação de slides (focada nas habilidades de assertividade e empatia) foi seguida de vídeos ilustrativos, estes prendiam a atenção dos atletas, propiciando uma discussão posterior mais produtiva. Em seguida, foi realizado o relato das tarefas de casa que consistiram em fazer uma gentileza/surpresa para qualquer colega e anotar como foi (qual situação foi? $\mathrm{O}$ que fez? O que sentiu? Explique porque você acha que foi assertivo e/ou empático). Este momento contou com certa empolgação dos participantes, apesar de dois atletas não se sentirem à vontade para relatar aos colegas as suas atividades.

Neste encontro, ainda, foi realizada a psicoeducação das distorções cognitivas, momento o qual os participantes mais se divertiram, se identificando com todas as distorções propostas e trazendo muitos exemplos de suas vidas. Foi notável que os atletas se envolveram muito nessa atividade, visto que conseguiram relacionar esta temática com o seu cotidiano, tanto as suas distorções quanto as de seus colegas. O clima ficou descontraído pela atmosfera de não julgamento e pela compreensão de que todos têm distorções cognitivas. Esta temática e o modelo cognitivo (pensamento-emoção-comportamento) foram recebidos com empolgação pelos atletas, de forma que um deles pediu para ficar após o encontro com a cópia do material explicativo das distorções cognitivas - que seria entregue na próxima sessão.

O quarto encontro, que retomava o assunto da semana anterior, também contou com a empolgação do grupo, apesar de em um primeiro momento entrarem no encontro desmotivados, assim como tinha acontecido nas semanas anteriores. Entretanto, a dinâmica planejada foi proposta para os minutos iniciais, fato que animou os participantes. A atividade consistia em dividir os atletas em dois grupos. Foi entregue uma cópia com todas as distorções cognitivas para cada atleta. Cada grupo devia fazer um role play, técnica que consiste na realização de uma encenação, com uma distorção cognitiva a qual o outro grupo devia adivinhar, de acordo com a apresentação feita pelas terapeutas e com o material de apoio entregue a eles. Logo no início da atividade eles demonstravam muito cuidado para que os adversários não escutassem 0 planejamento da encenação. Durante as apresentações, os atletas questionavam muito se o grupo adversário estava de fato representando a distorção a qual haviam se proposto e se isso não devia desqualificá-los, demonstrando que estavam levando a sério a atividade. Mesmo com a coordenadora explicando que a atividade não valia nenhum prêmio, os participantes levaram muito a sério e se mostraram muito competitivos.

Quando as coordenadoras entraram na explicação da temática original do encontro, engajamento, a atenção do grupo volta a se dispersar. No final da sessão, foi passada a tarefa de casa 'Linha da vida', onde os atletas foram instruídos a construir uma linha do tempo onde deveriam identificar os momentos mais importantes de sua vida, tanto os positivos quanto os considerados negativos. $O$ objetivo desta tarefa era 0 de levantar informações da vida dos participantes e estabelecer uma relação com a temática dos fatores de proteção e fatores de risco.

Já no quinto encontro, que trabalhava a temática da resiliência, na metade da intervenção, os participantes demonstravam um interesse crescente pela proposta, visto que cada vez mais participavam de forma ativa dos encontros, trazendo exemplos de suas vivências, ao mesmo tempo em que o compromisso de participar do projeto, somado às outras obrigações do clube, estava deixando-os cansados. Neste sentido, no início 
do quinto encontro um atleta verbalizou que estava exausto, pois haviam treinado pela manhã e no dia anterior. Além disso, perguntaram se o grupo controle não iria participar da intervenção também, dando a entender que estavam insatisfeitos por serem os únicos que deveriam comparecer aos encontros. Neste momento, as coordenadoras acolhem este desconforto, retomam as expectativas deles com a intervenção e relacionam com os benefícios que são objetivados com o processo. Desta forma, os atletas voltaram a se engajar no encontro, mais abertos às atividades. Foi realizada a psicoeducação acerca de fatores de risco e fatores de proteção (realizando uma relação com a tarefa da 'Linha da Vida'), e resiliência. Novamente, a utilização de vídeos mostrou-se uma abordagem efetiva para promover uma discussão produtiva entre eles. Foram utilizados vídeos que exemplificavam e ilustravam situações de superação de desafios.

O ponto das diferenças entre o cotidiano de atletas de futebol adolescentes e outros jovens da mesma idade apareceu novamente nesse encontro, quando as coordenadoras perguntaram justamente como eles percebiam essas discrepâncias. Um dos atletas relatou que sentia como se tivesse perdido sua adolescência, por ter assumido a responsabilidade da carreira futebolística. Assim, quando uma das coordenadoras questiona o porquê de eles estarem seguindo essa carreira, eles responderam: para ajudar a família, mas também pela fama e pelo sucesso.

Em seguida foi realizada a dinâmica que consistia que os atletas perambulassem pela sala ao som de uma música, que quando interrompida, deveriam se posicionar em cima de folhas de jornal que estavam no chão da sala. A cada rodada era retirada uma folha de jornal, sendo que os atletas deveriam buscar formas de compartilhar o espaço nas folhas restantes. No final da atividade, haveria apenas uma folha e eles precisariam arrumar alguma forma de compartilhar o pequeno espaço. Notou-se que os atletas realmente se engajaram na atividade, debatendo entre eles qual a melhor forma de proceder, levantando hipóteses e discutindo juntos para atingir o objetivo juntos. A resolução de problemas utilizada na atividade foi conectada ao conceito de resiliência, onde precisamos, apesar dos obstáculos ambientais, nos adaptarmos à uma nova demanda e pensarmos em novas maneiras de solucionar e lidar com tais obstáculos. Pode-se perceber que os atletas conseguiram dar sentido às atividades propostas nesta sessão, como os vídeos e a dinâmica, engajando-se nas discussões.

Assim como os atletas mostraram-se motivados no início da intervenção com a possibilidade de trabalhar questões referentes à ansiedade, de fato ele se engajaram nas sessões que abordaram esta temática. Dessa forma, no sexto encontro foi realizada a psicoeducação das manifestações e características da ansiedade, momento o qual eles discutiram a sua funcionalidade, os malefícios que ela tem para a saúde e refletiram sobre a influência das cognições nas nossas experiências cotidianas. Pode-se notar, ao longo do encontro, que mesmo durante a psicoeducação em slides, momento onde eles geralmente ficavam mais dispersos, mostraram-se atentos e engajados na discussão, dando exemplos pessoais (ex: pensamentos disfuncionais antes das partidas, reações fisiológicas percebidas em situações ameaçadoras, etc.). Ao longo do encontro, eles questionaram estratégias para diminuir a ansiedade, deram exemplos pessoais, nos quais conseguiram refletir sobre a funcionalidade de seus pensamentos frente a reflexões das coordenadoras.

Quando questionados quais pensamentos eles percebiam ter quando sentiam ansiedade em relação ao futebol, um dos participantes relatou: "sempre que vamos viajar para jogar eu penso que posso passar mal, penso que vou jogar tri mal". Outro atleta referiu: "penso: não vou comer café porque se não vou passar mal no jogo". Além disso, deram exemplos do contexto escolar, como "tenho medo de apresentar trabalhos na aula". Nesta ocasião, uma coordenadora conseguiu ajudá-lo a pensar na racionalidade deste pensamento que aparece em conjunto à ansiedade, pois de fato, na situação relatada, o atleta havia conseguido apresentar o trabalho sem problemas. Também, identificaram distorções cognitivas como a catastrofização, 
relacionando a temática atual com encontros anteriores. Mesmo assim, no final do encontro, eles aparentavam estar novamente distraídos frente ao seguimento da apresentação oral das coordenadoras após a discussão anterior.

Na sétima sessão, ao chegarem às dependências do clube, as coordenadoras foram informadas de que vários atletas foram desligados da instituição e alguns ainda estavam sendo chamados no horário da intervenção, inclusive dois que participavam do grupo experimental. Quando os participantes chegaram, pode-se perceber que eles estavam muito quietos e com um semblante abatido. Assim, as coordenadoras questionaram se eles gostariam de falar sobre o ocorrido, e eles optaram por seguir com o planejamento do encontro, para não ficarem pensando nisso. Desta forma, as coordenadoras retomaram a temática da ansiedade vista no encontro anterior, no entanto todos estavam de cabeça baixa, parecendo mentalmente distantes daquele momento.

Dessa forma, as coordenadoras julgaram mais adequado conversar sobre a situação das demissões, ainda que em um primeiro momento não tenha sido esta a escolha dos participantes. Eles conseguiram se abrir um pouco no grupo, expressando suas angústias pela incerteza do mantimento do contato com os colegas desligados do clube. Também relataram a importância que eles atribuem ao vínculo que criam no clube com os colegas e o quanto se sentem mais próximos uns dos outros. Entretanto, não aparentavam querer dar continuidade à discussão, de forma que as coordenadoras optaram por encerrar o encontro mais cedo.

$\mathrm{Na}$ oitava sessão, foi trabalhada a temática das habilidades de coping. Após a psicoeducação destas habilidades, os participantes deram ideias do que podem fazer para diminuir a ansiedade (ex: ouvir música, jogar videogame, treinar mais, etc.). Foi realizada a psicoeducação sobre técnicas de respiração para regulação de ansiedade, momento que prendeu a atenção dos participantes. Durante as demonstrações práticas dessa técnica, os atletas realizaram vários questionamentos sobre sua funcionalidade (ex: se é possível praticar a respiração durante os jogos, se é possível praticar a respiração para dormir melhor) além de pedir que as coordenadoras realizem a psicoeducação de diferentes modalidades de respiração, mesmo após elas sinalizarem que não iria dar tempo.

No último encontro, os participantes aproveitaram que as coordenadoras retomaram o assunto das técnicas de respiração, para um atleta que havia perdido a sessão anterior, para relatar os momentos que conseguiram colocá-las em prática. Foi proposto, em seguida, que os atletas preenchessem um Registro de Pensamentos Disfuncionais (RPD), atividade que consiste na descrição de pensamentos, emoções e comportamentos que surgem através de uma situação problema. Os atletas demonstraram pouco interesse nessa atividade, verbalizando que tinham preguiça de escrever tantas informações. Após finalizar o RPD, foram retomados os conceitos principais trabalhados ao longo dos oito encontros, e foi entregue um resumo para cada participante sobre os temas. Na sequência, foi solicitado feedback oral, onde os atletas deram às coordenadoras um retorno positivo, relatando que sentiam que os encontros pareciam aulas, pois aprendiam várias informações úteis não somente no contexto esportivo, mas para sua vida de forma mais ampla. Os atletas relataram ainda que sentiam que os conteúdos, por serem aplicáveis ao seu cotidiano, apresentavam relevância e faziam sentido para eles, mais do que aprendizagens escolares e atividades realizadas pelo clube.

\section{DISCUSSÃO}

A partir do relato de experiência, podem-se perceber diversas especificidades do trabalho com esta população. No que se refere ao Engajamento e Sentido dentro da prática esportiva, o relato dos participantes 
enfatiza o quanto o futebol Ihes traz prazer, fato que contribui positivamente para a construção da experiência profissional, principalmente tendo em vista o grande investimento (de tempo, físico, emocional, etc.) que é feito nesta carreira. Também se destaca como um dos aspectos que impacta a vivência desses jovens nesse contexto é a valorização do futebol pela cultura, visto que este esporte permeia as relações de amizade formadas entre estes adolescentes, suas relações profissionais, a constituição de seus ídolos ou figuras de referências e considerando também a valorização cultural do esporte na realidade brasileira (Ciampa et al., 2010).

Esta profissão também mostra sua influência no meio familiar, tendo em vista as verbalizações, no primeiro encontro, do quão são importantes estas relações para os participantes deste estudo, considerando-se que muitos deles relatam que um dos grandes motivos para o ingresso nesta carreira é a ajuda financeira às suas famílias. O prazer pela profissão e a busca pelo auxílio financeiro para os familiares, observados na intervenção, são informações que apresentam similaridade com outros achados de um estudo com atletas que também residem no Rio Grande do Sul (Pereira e Silva, 2015).

Pode-se notar que os participantes não demonstraram muito entusiasmo frente à proposta de trabalhar os elementos do bem-estar propostos pela Psicologia Positiva. Muitas vezes a psicoeducação e questionamentos das coordenadoras eram seguidos de momentos de silêncio. Após muito tempo sem falarem nada, algum atleta respondia pelo grupo. Em diversas situações, eles pareciam distraídos, rindo e fazendo brincadeiras que fugiam do contexto da atividade. Entretanto, os atletas retomavam o foco quando as coordenadoras usavam exemplos práticos dos conteúdos trabalhados e conseguiam passar estes conteúdos de maneira mais informal. Vale ressaltar que o encontro o qual seriam trabalhadas as técnicas de Psicologia Positiva teve que ser cancelado, por conta do cronograma da intervenção ter sido reduzido frente às variáveis intervenientes, como viagens e treinos dos atletas. Desta forma, estes conceitos não foram trabalhados de maneira pragmática, o que fragilizou, de certa forma, o tema.

Observa-se que a utilização de conceitos, como as distorções cognitivas, teve grande impacto no grupo pela forma contextualizada a qual foram abordadas, sempre trazendo exemplos do cotidiano dos participantes. Também se ressalta a importância das coordenadoras terem utilizado uma linguagem acessível, sempre fazendo relação das temáticas com vivências diárias do contexto esportivo (Souza, Pachito, Biaggi e Neufeld, 2007). Desta forma, os atletas puderam relacionar esta temática às vivências de seus cotidianos, reconhecendo que de fato todos os indivíduos possuem formas enviesadas de compreender as situações e o quanto estas percepções incorretas podem afetar a qualidade da experiência na categoria de base.

Quanto ao esporte de alto rendimento, os atletas adolescentes se encontram em uma situação complexa, onde podem estar obtendo cada vez mais independência dos pais e buscando relações mais significativas como colegas (Souza, Pachito, Biaggi e Neufeld, 2007). Frente esta questão, se nota o impacto da fala dos participantes quanto a abdicações de experiências típicas desta faixa etária, resultante do engajamento nesta carreira, e a importância da promoção de habilidades para o enfrentamento desta realidade. Neste sentido, a importância que os participantes deste estudo dão para o vínculo que eles têm, pode se configurar como um fator de proteção, tendo em vista que os aspectos social e relacional, juntamente com as características individuais de cada um, são fatores fundamentais do desenvolvimento da identidade, principalmente nesta faixa etária (Rodríguez e Damásio, 2014).

No que se refere às atividades práticas, pode-se perceber que a utilização de dinâmicas de grupo pôde ajudar na adesão dos participantes às temáticas trabalhadas, principalmente as que tinham um caráter competitivo. Nesta intervenção, avaliou-se que atividades de competição (como o "teatro/role-play" das 
distorções cognitivas) foram as que os atletas mais se engajaram, além de melhorar a motivação para 0 restante do encontro. Ao mesmo tempo, deve-se ter o cuidado de não reforçar o valor de que "quem vence é o melhor". Neste tipo de atividade deve estar sempre claro que o importante não é vencer o desafio, mas aprender por meio da cooperação entre grupos.

Também, se discute a valorização por parte dos atletas pelas técnicas trabalhadas na intervenção para 0 manejo de ansiedade e de reações fisiológicas ao estresse. Compreende-se que o grande interesse dos participantes nas sessões nas quais foram abordadas estas temáticas pode refletir a identificação de dificuldades por parte dos atletas para dar conta de todas as demandas que eles precisam atender, como a rotina de treinamentos e campeonatos, somada às obrigações escolares do turno inverso. Discorre-se também sobre como os atletas davam retornos positivos para o trabalho com o treinamento de habilidades de coping e manejo de ansiedade, mesmo explicitando que o comparecimento nos encontros acabava por tornar suas rotinas mais desgastantes. Uma compreensão possível para este bom aproveitamento é que os participantes entenderam a importância de sua própria maneira subjetiva de lidar com as adversidades. Nesta perspectiva, defende-se que a intensidade da vivência do estresse por estes atletas, mesmo na presença de fatores de risco em seu ambiente, depende não somente destes fatores externos, mas também da interação de atributos individuais, os quais foram justamente abordados nesta etapa da intervenção, como as estratégias de enfrentamento e a capacidade de resiliência (Lipp, 2014).

Um ponto que também chama atenção é o fato de que os fatores estressantes vão aumentando, e as equipes vão tendo maior pressão externa para ganhar, conforme a carreira do atleta vai avançando nas categorias (Nascimento Junior, Gaion, Nakashima e Vieira, 2011). Somada esta pressão característica do ambiente, está o fato de que transtornos de ansiedade estão entre os transtornos mentais mais comumente experimentados pelos adolescentes, associando-se a significativos prejuízos e redução na qualidade de vida (Farrell, Milosevic e Mccabe, 2015). Mesmo que nenhum dos participantes deste estudo tenha apresentado, na avaliação inicial, níveis que caracterizassem um quadro de ansiedade, este dado explicita a importância de projetos que possam investigar e prevenir fatores de risco no ambiente destes jovens, principalmente no contexto de esporte de alto rendimento.

Conclui-se que para o trabalho com atletas de alto rendimento de categoria de base, o profissional necessita compreender as demandas destes adolescentes e o meio o qual estão inseridos, além de adaptar sua linguagem para esta faixa etária. A criação de um vínculo entre as coordenadoras e o grupo de intervenção pode ser apontada como uma boa preditora do bom andamento dos encontros. Por fim, sugere-se que as considerações realizadas neste relato de experiência possibilitem que outros pesquisadores possam ter uma visão mais ampla e contextualizada da aplicação de intervenções similares e permitam reflexões frente à possibilidade de replicação no seu próprio campo de atuação.

\section{REFERENCES}

Bieling, P. J., McCabe, R. E., e Antony. M. M. (2008). Terapia cognitivo-comportamental em grupos. Porto Alegre: Artmed.

Butler, A. C., Chapman, J. E., Forman, E. M., e Beck, A. T. (2006). The empirical status of cognitivebehavioral therapy: A review of meta-analyses. Clinical Psychology Review, 26, 17-31. https://doi.org/10.1016/i.cpr.2005.07.003

Caputo, E. L., Rombaldi, A. J., e da Silva, M. C. (2017). Sintomas de estresse pré-competitivo em atletas adolescentes de handebol. Revista Brasileira de Ciências do Esporte, 39(1), 68-72. https://doi.org/10.1016/..rbce.2016.01.006 
Ciampa, A. C., Leme, C. G., Souza, R. F. (2010). Considerações sobre a formação e transformação da identidade profissional do atleta de futebol no Brasil. Revista Diversitas - Perspectivas en Psicología, 6, 27-36. Retrieved from http://www.scielo.org.co/pdf/dpp/v6n1/v6n1a03.pdf

Engebretsen, A. H., Myklebust, G., Holme, I., Engebretsen, L., e Bahr, R. (2008). Prevention of Injuries Among Male Soccer Players A Prospective, Randomized Intervention Study Targeting Players With Previous Injuries or Reduced Function. The American journal of sports medicine, 36(6), 1052-1060. https://doi.org/10.1177/0363546508314432

Farrell, N. R., Milosevic, I., e Mccabe, R. E. (2015). Terapia Cognitivo-comportamental em grupo para adolescentes com transtornos de ansiedade. In Neufield, C. B. Terapia cognitivo-comportamental em grupo para crianças e adolescentes. Porto Alegre: Artmed. https://doi.org/10.11606/d.5.2010.tde-27082010-172817

Knapp, P., e Beck, A. T. (2008). Fundamentos, modelos conceituais, aplicações e pesquisa da terapia cognitiva Cognitive therapy: foundations, conceptual models, applications and research. Revista Brasileira de Psiquiatria, 30(Supl II), S54-64. https://doi.org/10.1590/s1516-44462008000600002

Lipp, E. N. M. (2014). Compreendendo o Stress Emocional. In: Lipp, E. N. M. e Tricoli, V. Relacionamentos Interpessoais no século XXI e o stress emocional. Novo Hamburgo: Synopsys.

Luz, J. M. O., Murta, S. G., e Aquino, T. A. A. (2015). Programas de promoção de saúde mental em grupo para adolescentes. In: Neufield, C. B. Terapia cognitivo-comportamental em grupo para crianças e adolescentes. Porto Alegre: Artmed. https://doi.org/10.11606/t.59.2011.tde-21102013160131

Murta, S. G. (2007). Programas de prevenção a problemas emocionais e comportamentais em crianças e adolescentes: lições de três décadas de pesquisa. Psicologia: Reflexão e Crítica, 20(1), 1-8. https://doi.org/10.1590/s0102-79722007000100002

Nascimento Junior, J. R. A. D., Gaion, P. A., Nakashima, F. S. e Vieira, L. F. (2011). Análise do estresse psicológico pré-competitivo e estratégias de coping de jovens atletas de futebol de campo. Revista Brasileira de Ciência e Movimento, 18(4), 45-53. https://doi.org/10.5007/1980-0037.2012v14n6p704

Paína, D. M., Fechio, J. J., Peccin, M. S., e da Costa Padovani, R. (2018). Avaliação da qualidade de vida, estresse, ansiedade e coping de jogadores de futebol de campo da categoria sub-20. Contextos Clínicos, 11(1), 97-105. https://doi.org/10.4013/ctc.2018.111.08

Paludo, S. S. e Koller, S. H. (2007). Psicologia Positiva: uma nova abordagem para antigas questões. Paidéia, 17(36), 9-20. https://doi.org/10.1590/s0103-863×2007000100002

Pereira, A. M. e Silva, M. C. (2015). Perfil e perspectivas de jogadores das categorias sub-13 e sub-15 de clubes profissionais de futebol de campo da cidade de Pelotas - RS. Revista Brasileira de Futsal e Futebol, 7(25), 342-348. https://doi.org/10.5585/podium.v6i4.212

Rodríguez, S. N., e Damásio, B. F. (2014). Desenvolvimento da identidade e do sentido de vida na adolescência. In: Habigzang, L. F., Diniz, E., e Koller, S. H. Trabalhando com adolescentes: teoria e intervenção psicológica. Porto Alegre: Artmed.

Sanches, S. M. (2007). A prática esportiva como uma atividade potencialmente promotora de resiliência. Revista Brasileira de Psicologia do Esporte ,1(1), 01-15. https://doi.org/10.31501/rbpe.v1i1.9256

Sanches, S. M. (2018). Um olhar positivo sobre a psicologia do esporte: contribuições da psicologia positiva. Revista Brasileira de Psicologia do Esporte, 2(2). https://doi.org/10.31501/rbpe.v2i2.9284

Santos, F. S., Maia, C. R. C., Faedo, F. C., Gomes, G. P. C., Nunes, M. E., e Oliveira, M. V. M. D. (2017). Stress among Pre-University and Undergraduate Medical Students. Revista Brasileira de Educação Médica, 41(2), 194-200. https://doi.org/10.1590/1981-52712015v41n2rb20150047

Silva, A. M. B., Enumo, S. R. F., de Morais Afonso, R., de Francisco Carvalho, L., de Araújo, M. F., Bittencourt, I. G., e Luz, T. S. R. (2017). Lista de Sintomas de Stress Pré-competitivo Infanto-juvenil: 
Adaptação para Bailarinos. Revista iberoamericana de diagnóstico y evaluación psicológica, 43(1), 59-70. https://doi.org/10.21865/ridep43 59

Souza, V. C., Pachito, D. V., Biaggi, D. e Neufeld, C. B. (2017). In: Atividade física, esporte e sono na adolescência. In: Neufeld, C. M. Terapia cognitivo-comportamental para adolescentes: uma perspectiva transdiagnóstica e desenvolvimental. Porto Alegre: Artmed.

Steffen, K., Bakka, H. M., Myklebust, G., e Bahr, R. (2008). Performance aspects of an injury prevention program: a ten-week intervention in adolescent female football players. Scandinavian journal of medicine e science in sports, 18(5), 596-604. https://doi.org/10.1111/j.1600-0838.2007.00708.x

Van Beijsterveldt, A. M. C., van der Horst, N., van de Port, I. G., e Backx, F. J. (2013). How effective are exercise-based injury prevention programmes for soccer players?. Sports Medicine, 43(4), 257-265. https://doi.org/10.1007/s40279-013-0026-0

WHO: World Health Organization, Department of Mental Health and Substance Dependence. (2001). Prevention and Promotion in Mental Health. Geneva.

Wright, J. H.; Basco, M. R.; Thase, M. E. (2008). Aprendendo a Terapia Cognitivo-comportamental. Porto Alegre: Artmed.

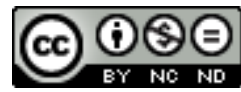

This work is licensed under a Attribution-NonCommercial-NoDerivatives 4.0 International (CC BY-NC-ND 4.0). 